$N G R-09-015=002$

Smithsonian Trstitote

SOLAR-WIND DEPENDENCE OF THE DIURNAL NASA CR 109523 TEMPERATURE VARIATION IN THE THERMOSPHERE

L. G. JACCHIA

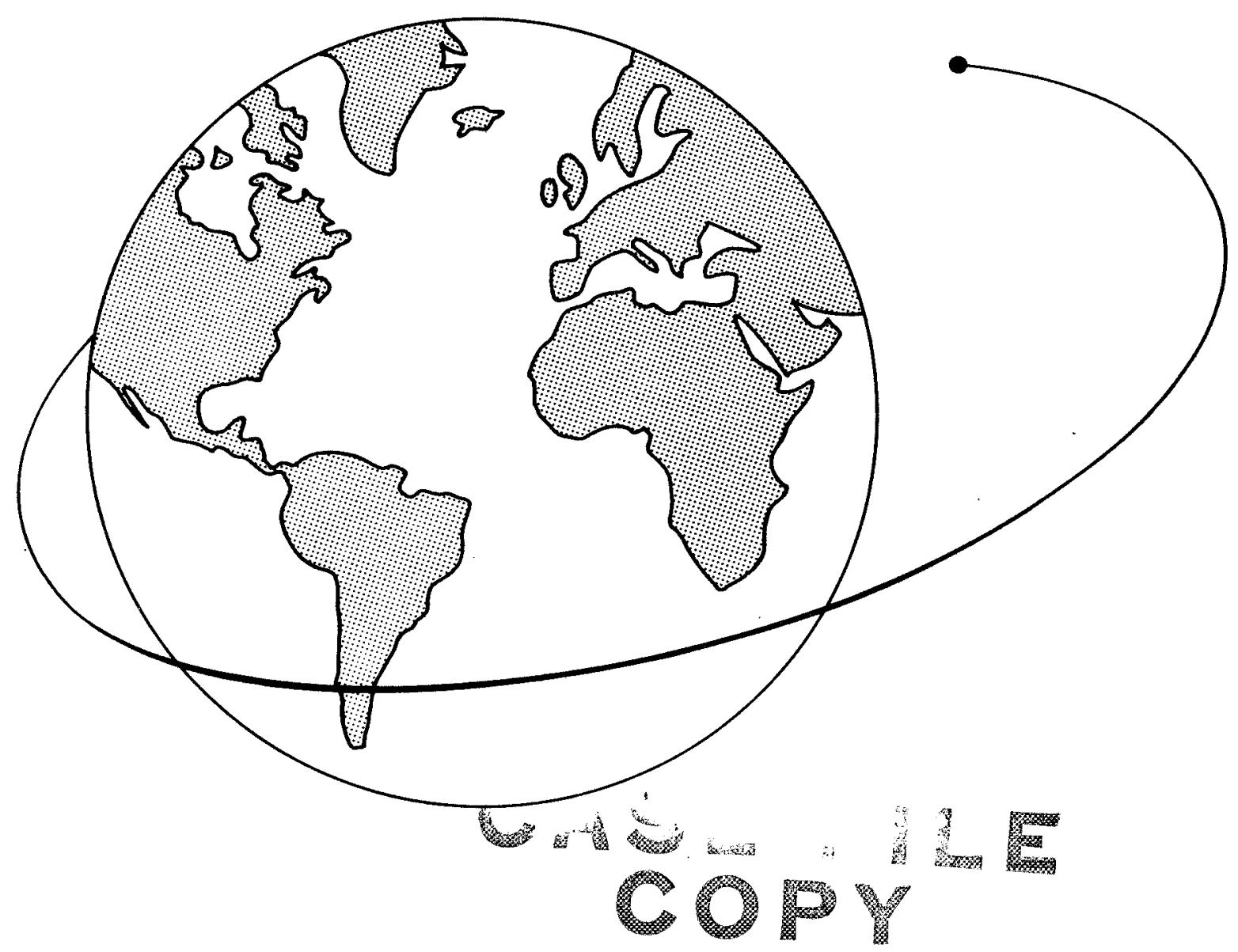

Smithsonian Astrophysical Observatory SPECIAL REPORT 311 
Research in Space Science

SAO Special Report No. 311

SOLAR-WIND DEPENDENCE OF THE DIURNAL TEMPERATURE

VARIATION IN THE THERMOSPHERE

Luigi G. Jacchia

March 27, 1970

Smiths onian Institution Astrophysical Observatory Cambridge, Massachusetts 02138 
TABLE OF CONTENTS

$\underline{\text { Page }}$

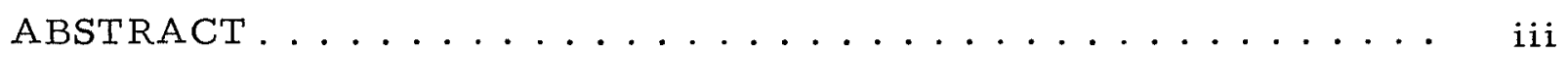

SOLAR - WIND DEPENDENCE OF THE DIURNAL TEMPERATURE

VARIATION IN THE THERMOSPHERE. . . . . . . . . . . . . 1

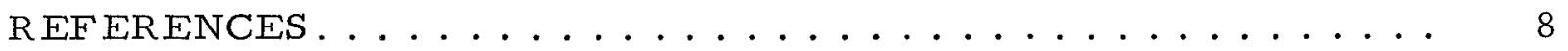




\begin{abstract}
ABST RACT
The ratio $\mathrm{r}=\mathrm{T}_{\max } / \mathrm{T}_{\text {min }}$ of the maximum to the minimum exospheric temperature considered on a global scale was derived by means of static models using the densities obtained from the atmospheric drag of three low-inclination satellites. It is found that $r$ varies with the solar cycle, lagging more than a year behind the variations of the $10.7-\mathrm{cm}$ solar flux; on the other hand, the variations of $r$ are in phase with $\bar{K}_{p}$, which is obtained by averaging the planetary geomagnetic index $\mathrm{K}_{\mathrm{p}}$ over the whole year. The obvious conclusion is that in the mechanism of the diurnal temperature variation in the thermosphere, the solar wind is at least as important as, if not more important than, solar EUV. No appreciable lag is found in the variation of the minimum nighttime temperature when compared with the variations of the $10.7-\mathrm{cm}$ solar flux.
\end{abstract}


A l'aide de modèles statiques employant les densités obtenues à partir du ralentissement, dû̀ l'atmosphère, de trois satellites à faible inclinaison, on déduit le rapport $r=T_{\max } / T_{\min } d u$ maximum et du minimum de la température exosphérique, considérée sur une échelle glabale. On a trauvé que r varie avec le cycle solaire, étant en retard de plus d'une année sur les variations du flux solaire à $10,7 \mathrm{~cm}$; d'un autre côté les variations de I sont en phase avec $\bar{K}_{p}$, qui est obtenu en prenant la moyenne de l'indice géomagnétique planétaire $K_{p}$ sur taute l'année. La conclusion évidente est que le vent solaire est au moins aussi important, sinon plus important, que l'UVE solaire dans le méchanisme de la variation de la température diurne dans la thermosphère. Nous n'avons pas trouvé de retard appréciable dans la variation de la température nocturne minimum quand on la compare avec les variations du flux solaire à $10,7 \mathrm{~cm}$.

\section{KOHCПEКT}

Отношение $r=T_{\text {мaкd }} T_{\text {мин }}$ максимальной температуры экзосферы к минимальной по глобальной шкале было получено при помощи статичных моделей, использующих плотности, вычисленные из атмосферното побового сопротивления трех низко-запущенных спутников. обнаружено что г зависит от солнечного обращения, отставая более, чем на год от изменений солнечного потока в 10,7 см; с другой стороны, изменения г совпадают по фазе с $\overline{\mathrm{K}}_{\mathrm{p}}$, которое получено путем усереднения планетарного геомагнитного индекса $K_{p}$ за год. Очевиден вывод что в механизме дневного изменения термосферы солнечный ветер, по крайней мере, также важен, если не важнее, солнечных EUV. Было обнаружено незначительное отставание в изменении минимальной ночной температуры в сравнении с изменением солнечного потока в 10,7 см. 


\title{
SOLAR - WIND DEPENDENCE OF THE DIURNAL TEMPERATURE VARIATION IN THE THERMOSPHERE
}

\author{
Luigi G. Jacchia
}

It was pointed out long ago (Jacchia, 1961) that the range of the diurnal density variations in the upper atmosphere derived from satellite drag can be approximated by assuming that the ratio $r=T_{\max } / \mathrm{T}_{\min }$ of the maximum to the minimum exospheric temperature considered on a global scale is a constant; with use of Nicolet's (1961) static models, a value of 1.35 was derived for this constant. The constancy of $r$ is, of course, only an empirical approximation that cannot be expected to hold rigorously. As a matter of fact, it was later found (Jacchia and Slowey, 1968) that in the time interval from 1958 to 1966 , $r$ underwent appreciable variations that appeared to be only loosely related to the solar cycle. Although there seemed to be a general tendency for $r$ to be smaller at sunspot minimum than at sunspot maximum, no justification on the basis of solar activity could be found for a remarkable drop in the value of $r$ that occurred in 1963, when solar activity was practically at its minimum.

Recent observations show that $r$ recovered in 1967. A plot of all the values of $\mathbf{r}$ derived from three low-inclination satellites is shown in Figure 1. The temperatures used in computing $r$ were derived with the aid of new

This work was supported in part by grant NGR 09-015-002 from the National Aeronautics and Space Administration. 

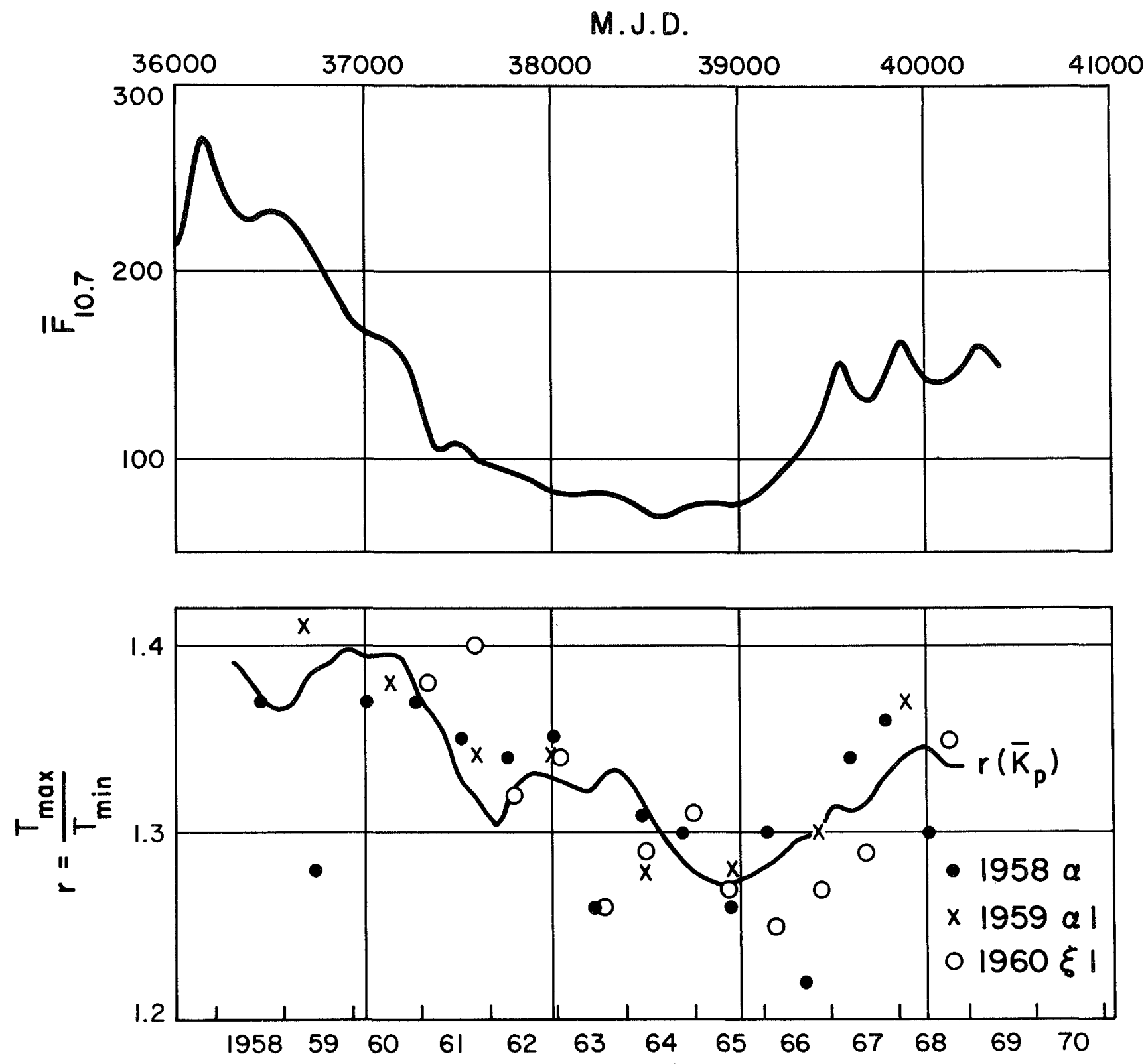

Figure 1. Individual values of the ratio $\mathrm{T}_{\max } / \mathrm{T}_{\min }$ in the diurnal. temperature variation (lower section) compared with the smoothed 10.7-cm solar flux $\bar{F}_{10.7}$ (upper section) and with the curve of $\mathrm{r}$ computed from $\overline{\mathrm{K}}_{\mathrm{p}}$ by equation (1). 
atmospheric models prepared by the author for the forthcoming revision of the COSPAR International Reference Atmosphere (actually, it makes very little difference whether one or another set of models is used). The temperatures were corrected to account for the day-to-day solar activity effect and the semiannual variation and were reduced to quiet geomagnetic conditions $\left(K_{p}=0\right)$. A curve of $\bar{F}_{10.7}$, the $10.7-\mathrm{cm}$ solar flux smoothed ove $\mathrm{r}$ approximately three solar rotations is shown in the upper half of Figure 1 . A comparison of this curve with the observed values of $r$ shows that the variation of the latter lags behind the solar-flux curve by more than a year (about 2 years during the declining phase of the solar cycle and about a year during the rising phase).

As is well known, the $10.7-\mathrm{cm}$ solar flux is in phase with the variation of the sunspot numbers and sunspot areas (Ward and Shapiro, 1962) and is generally believed to be a good second-hand index of the integrated EUV emission from the solar disk. There is an excellent correlation between the nighttime minimum of the exospheric temperature and the 10.7-cm solar flux, which has generally been interpreted as indicating that solar EUV is mainly responsible for the heating of the thermosphere. If the diurnal temperature variation were caused only by the change of illumination by the solar EUV source owing to the earth's rotation, the variation of the ratio $r$ should be in phase with the variation of solar EUV and therefore with the $10.7-\mathrm{cm}$ solar flux; a lag of 1 year or more would be impossible to justify on the basis of this hypothesis. However, a lag of 1 year or more behind solar activity does exist, as is well known, in the variation of geomagnetic activity, owing to the change in heliographic latitude of active areas in the course of 
the solar cycle. A plot of the ratio $r$ against 365 -day running means $\bar{K}_{p}$ of the planetary geomagnetic index $\mathrm{K}_{\mathrm{p}}$ computed at 100-day intervals shows a rather satisfactory relation (Figure 2). The correlation coefficient between $r$ and $\overline{\mathrm{K}}_{\mathrm{p}}$ is 0.73 , as compared with 0.59 in the correlation between $\mathbf{r}$ and $\overline{\mathrm{F}}_{10.7^{\circ}}$

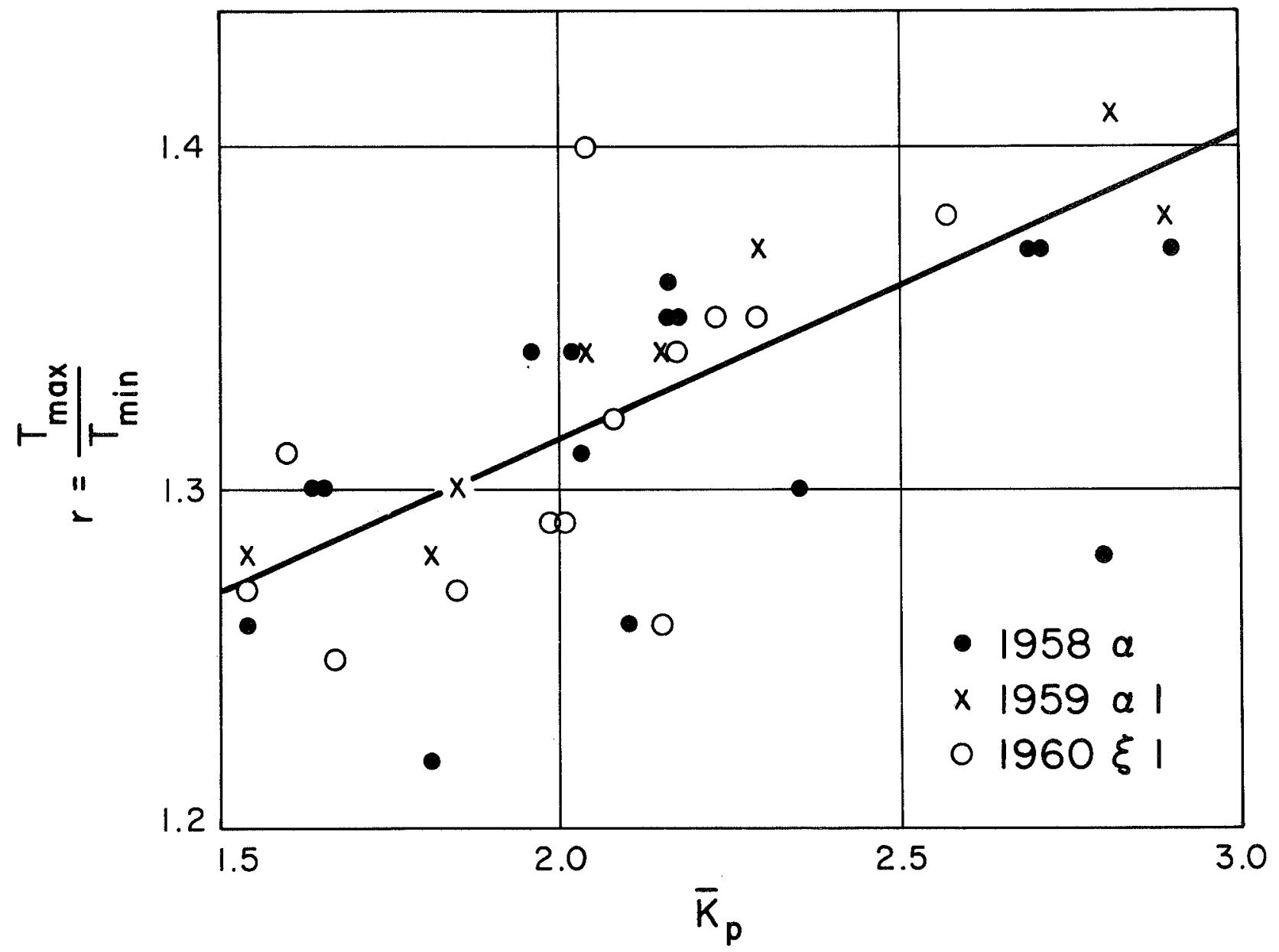

Figure 2. Values of $\mathrm{T}_{\max } / \mathrm{T}_{\min }$ plotted against $\overline{\mathrm{K}}_{\mathrm{p}}$. The regression line is from equation ( 1 ).

The reason for taking 365-day running means of $\mathrm{K}_{\mathrm{p}}$ is that by doing so we eliminate the semiannual increase in $\mathrm{K}_{\mathrm{p}}$ around the equinoxes. By least squares we obtain the following linear correlation: 


$$
\begin{aligned}
r= & 1.134+0.090 \overline{\mathrm{K}}_{\mathrm{p}} \\
& \pm 0.031 \pm 0.014 \text { (S. D.) }
\end{aligned}
$$

The curve of $r$ computed by equation (1) is shown in the lower half of Figure 1 . A lag of about 1 year behind the $\overline{\mathrm{F}}_{10.7}$ curve is quite evident, as well as a fair agreement with the observed variation of $r$.

The obvious conclusion that, however reluctantly, must be drawn from the relation between $r$ and $\bar{K}_{p}$ is that in the mechanism of the diurnal temperature variation of the thermosphere and exosphere, the solar wind is at least as important as, if not more important than, solar EUV. This hypothesis is not entirely new: it was already invoked by Harris and Priester (1962) to explain the discrepancy between the actual diurnal variation and the theoretical variation they obtained using solar EUV as the sole best source. In view of the uncertainties and oversimplifications in the theory, however, their introduction of an ad hoc second source out of phase with the EUV source is generally regarded as not physically meaningful.

It is interesting to note that no lag is evident in the relation between the minimum night temperature $T_{\text {min }}$ and the $10.7-\mathrm{cm}$ solar flux. Figure 3 shows values of $T_{\text {min }}$ (reduced to quiet geomagnetic conditions, $K_{p}=0$, just as were the maximum temperatures $\mathrm{T}_{\text {max }}$ used for the computation of $r$ ) derived from the drag of the Explorer 1 satellite. Only one satellite was selected, to ensure greater uniformity in the data. Dots indicate data from the declining phase of solar activity, before the 1964 minimum; data from the rising phase after mid-1964 are marked as open circles. As can be seen, the 


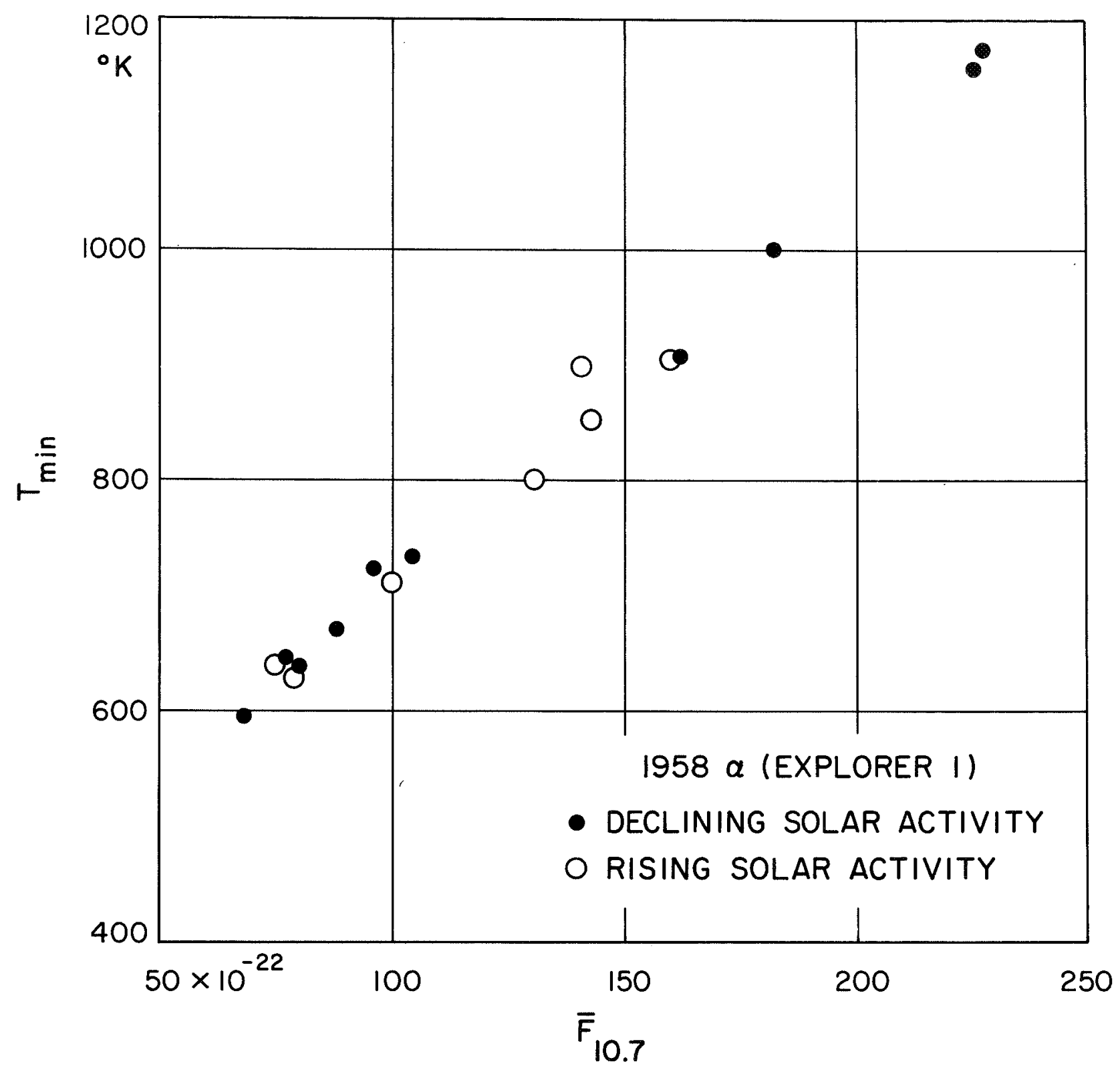

Figure 3. Minimum nighttime temperatures $\mathrm{T}_{\text {min }}$ derived from the drag of Satellite 1958 a (Explorer 1) during declining solar activity (dots) and rising solar activity (open circles). 
data from the declining phase and those from the rising phase agree without any appreciable systematic difference. Clearly, if there is a phase lag in the daytime temperatures, there must also be some lag in the nighttime temperatures; it appears, however, that the lag in the nighttime temperatures is much smaller, to the point where it cannot be detected.

The dependence of $r$ on $\bar{K}_{p}$ rather than on $\bar{F}_{10.7}$ poses the problem of a practical nature in the analysis and prediction of atmospheric densities by means of models, because $\overline{\mathrm{K}}_{\mathrm{p}}$ can be obtained only with a delay of nearly a year. For the reduction of current atmospheric data, it may be preferable to compute $r$ by use of $\bar{F}_{10.7}$ with a suitable lag. We find that the formula

$$
r=0.81+0.25 \log \bar{F}_{10.7}\left(t-400^{d}\right)
$$

is quite satisfactory; $\bar{F}_{10.7}\left(t-400^{d}\right)$ stands for $\bar{F}_{10.7}$ at the time $t$ minus 400 days. 


\section{REFERENCES}

HARRIS, I. , AND PRIESTER, W.

1962. Time-dependent structure of the upper atmosphere. Journ.

Atmos. Sci., vol. 19, pp. 286-301.

JACCHIA, L. G.

1961. A working model for the upper atmosphere. Nature, vol. 192, pp. $1147-1148$.

JACCHIA, L. G. , AND SLOWEY, J.

1968. Diurnal and seasonal latitudinal variations in the upper atmosphere. Planet. Space Sci., vol. 16, pp. 509-524.

NICOLET, M.

1961. Density of the heterosphere related to temperature. Smithsonian Astrophys. Obs. Spec. Rep. No. 75, 30 pp.

WARD, F., AND SHAPIRO, R.

1962. Decomposition and comparison of time series of indices of solar activity. Journ. Geophys. Res., vol. 67, pp. 541-554. 


\section{BIOGRAPHICAL NOTE}

LUIGI G. JACCHIA received his doctorate from the University of Bologna in 1932. He continued working with the university as an astronomer at its observatory.

Dr. Jacchia's affiliation with Harvard College Observatory began with his appointment as research associate in 1939. At that time he was studying variable stars. Since joining SAO as a physicist in 1956, most of Dr. Jacchia's work has been on meteors and upper atmospheric research. 
NOTICE

This series of Special Reports was instituted under the supervision of Dr. F. L. Whipple, Director of the Astrophysical Observatory of the Smithsonian Institution, shortly after the launching of the first artificial earth satellite on October 4, 1957. Contributions come from the Staff of the Observatory.

First is sued to ensure the immediate dissemination of data for satellite tracking, the reports have continued to provide a rapid distribution of catalogs of satellite observations, orbital information, and preliminary results of data analyses prior to formal publication in the appropriate journals. The Reports are also used extensively for the rapid publication of preliminary or special results in other fields of astrophysics.

The Reports are regularly distributed to all institutions participating in the U.S. space research program and to individual scientists who request them from the Publications Division, Distribution Section, Smithsonian Astrophysical Observatory, Cambridge, Massachusetts 02138 . 